This item was submitted to Loughborough's Research Repository by the author.

Items in Figshare are protected by copyright, with all rights reserved, unless otherwise indicated.

\title{
Hydrogen peroxide production in an atmospheric pressure RF glow discharge: comparison of models and experiments
}

PLEASE CITE THE PUBLISHED VERSION

http://dx.doi.org/10.1007/s11090-014-9559-8

\section{PUBLISHER}

(C) Springer Science+Business Media

\section{VERSION}

AM (Accepted Manuscript)

\section{LICENCE}

CC BY-NC-ND 4.0

\section{REPOSITORY RECORD}

Vasko, C.A., Ding-Xin Liu, E.M. van Veldhuizen, Felipe Iza, and Peter Bruggeman. 2019. "Hydrogen Peroxide Production in an Atmospheric Pressure RF Glow Discharge: Comparison of Models and Experiments". figshare. https://hdl.handle.net/2134/15668. 
$\mathrm{H}_{2} \mathrm{O}_{2}$ production in an atmospheric pressure $\mathrm{RF}$ glow discharge: comparison of models and experiments 


\title{
Hydrogen peroxide production in an atmospheric pressure RF glow discharge: comparison of models and experiments
}

\author{
C.A. Vasko - D.X. Liu - E.M. van Veldhuizen - F. \\ Iza · P.J. Bruggeman
}

Received: date / Accepted: date

\begin{abstract}
The production of $\mathrm{H}_{2} \mathrm{O}_{2}$ in an atmospheric pressure RF glow discharge in helium - water vapor mixtures has been investigated as a function of plasma dissipated power, water concentration, gas flow (residence time) and power modulation of the plasma. $\mathrm{H}_{2} \mathrm{O}_{2}$ concentrations up to $8 \mathrm{ppm}$ in the gas phase and a maximum energy efficiency of $0.12 \mathrm{~g} / \mathrm{kWh}$ are found. The experimental results are compared with a previously reported global chemical kinetics model and a 1 dimensional fluid model to investigate the chemical processes involved in $\mathrm{H}_{2} \mathrm{O}_{2}$ production. An analytical balance of the main production and destruction mechanisms of $\mathrm{H}_{2} \mathrm{O}_{2}$ is made which is refined by a comparison of the experimental data with a previously published global kinetic model and a $1 \mathrm{D}$ fluid model. In addition, the experiments are used to validate and refine the computational models. Accuracies of both model and experiment are discussed.
\end{abstract}

C.A. Vasko

Eindhoven University of Technology, Department of Applied Physics, P.O. Box 513, 5600 MB Eindhoven, The Netherlands

D.X. Liu

State Key Laboratory of Electrical Insulation and Power Equipment, Xi'an Jiaotong University, 710049, People's Republic of China

E.M. van Veldhuizen

Eindhoven University of Technology, Department of Applied Physics, P.O. Box 513, 5600 MB Eindhoven, The Netherlands

F. Iza

School of Electronic, Electrical and Systems Engineering, Loughborough University, LE11 3TU, UK

P.J. Bruggeman

Eindhoven University of Technology, Department of Applied Physics, P.O. Box 513, 5600 MB Eindhoven, The Netherlands University of Minnesota, Department of Mechanical Engineering, 111 Church Street SE, Minneapolis, MN55455, USA 


\section{Introduction}

The chemistry of non-equilibrium atmospheric pressure plasmas in the presence of water has been in the focus of interest of many research groups in the past years. These discharges can produce a great amount of reactive species, including $\mathrm{O}, \mathrm{OH}$ and $\mathrm{H}_{2} \mathrm{O}_{2}$ [1]. A better understanding of underlying mechanisms and dependencies of the production of these reactive species may benefit many different applications ranging from biomedical applications over air treatment to chemical synthesis. Of these reactive species, hydrogen peroxide $\left(\mathrm{H}_{2} \mathrm{O}_{2}\right)$ is an important oxidant due to its high active oxygen content $(\sim 50 \%)$ [2]. Further, it can be considered as a green alternative in a wide range of applications [1,3], as the byproduct of oxidizing reactions involving hydrogen peroxide in controlled environments is only water [4]. The applications cover a range from industrial/communal waste water treatment [5-7], stain free detergents [7], and as oxidant for industrial scale catalytic processes to interesting biological applications such as disinfection, bleaching and wound healing [8]. Non-equilibrium atmospheric pressure plasmas may thus provide the possibility to produce $\mathrm{H}_{2} \mathrm{O}_{2}$ from $\mathrm{H}_{2} \mathrm{O}$ in an environmentally friendly manner for many of these applications.

A recent review by Locke et al. [9] shows that in the past decades a number of different gas discharges have been investigated for $\mathrm{H}_{2} \mathrm{O}_{2}$ production. The energy efficiency $(\eta)$, defined as mass of $\mathrm{H}_{2} \mathrm{O}_{2}$ produced per dissipated energy $[\mathrm{g} / \mathrm{kWh}$, allows a comparison of these different production methods. Production efficiency in the gas phase covers a wide range of more than two orders of magnitude from 0.1 to $80 \mathrm{~g} / \mathrm{kWh}$ (table 1). The detailed dependencies of $\mathrm{H}_{2} \mathrm{O}_{2}$ production and destruction in a plasma are not well understood and fail to quantitatively explain such a wide range of efficiencies. This makes direct comparison of fundamentally different discharges (such as corona (-like) discharges, dielectric barrier discharges (DBDs), plasmas in contact with liquids, in bubbles or directly in a liquid) a challenging task. Diffuse atmospheric pressure RF glow discharges (APGDs) offer certain advantages to investigate key plasma parameters to hydrogen peroxide production, such as low gas temperature, well defined residence time and a homogeneous discharge allowing a uniform treatment of the gas. Modeling results of a homogeneous APGD in helium-water by Liu et al. [10] showed modeled production efficiencies of $\mathrm{H}_{2} \mathrm{O}_{2}$ in the order of tens of $\mathrm{g} / \mathrm{kWh}$. In addition the diffuse discharge generated in a parallel plate geometry allows to reduce a fluid model of the discharge to one dimension. All the above motivates why an APGD is chosen to investigate the $\mathrm{H}_{2} \mathrm{O}_{2}$ production in a cold non - equilibrium atmospheric pressure plasma.

In this work we present results on the gas phase $\mathrm{H}_{2} \mathrm{O}_{2}$ production in a $\mathrm{He}+\mathrm{H}_{2} \mathrm{O} R F$ driven APGD. The measurements are complemented with accurate gas temperature $\left(T_{\text {gas }}\right)$ measurements and plasma dissipated power measurements. In addition the experimental results are compared with a previously published global model [10] and 1D fluid model [11]. An analysis of the production and destruction mechanisms of $\mathrm{H}_{2} \mathrm{O}_{2}$ is made with a simplified analytical balance equation of the $\mathrm{H}_{2} \mathrm{O}_{2}$ production based on extensive chemistry models.

The experimental setup and diagnostics used are presented first. Next, the details of the models and modifications are presented. The influence of power, water concentration, power modulation and residence time (flow) on the $\mathrm{H}_{2} \mathrm{O}_{2}$ is presented. Finally, the production and destruction mechanisms of $\mathrm{H}_{2} \mathrm{O}_{2}$ are examined analytically and compared with a global model and 1D fluid model for a particular experimental setting. 
Table 1: Overview of the energy efficiencies of hydrogen peroxide production methods in gas phase plasmas containing $\mathrm{H}_{2} \mathrm{O}$ as reported in literature. The highest production reported in this work is also included. A more detailed overview can be found in [9].

\begin{tabular}{llll}
\hline Gas Mixture & Discharge type & $\eta[\mathrm{g} / \mathrm{kWh}]$ & Reference \\
\hline $\mathrm{Ar}+\mathrm{H}_{2} \mathrm{O}$ & DBD & 1.7 & {$[12]$} \\
$\mathrm{Ar}+\mathrm{H}_{2} \mathrm{O}$ & DBD & 0.14 & {$[13]$} \\
$\mathrm{Ar} /$ water spray & Pulsed Gliding Arc & 80.0 & {$[14]$} \\
$\mathrm{Steam}$ & MW + supersonic expansion & 24.0 & {$[15]$} \\
$\mathrm{He}+\mathrm{H}_{2} \mathrm{O}$ & APGD & 0.12 & this work \\
\hline
\end{tabular}

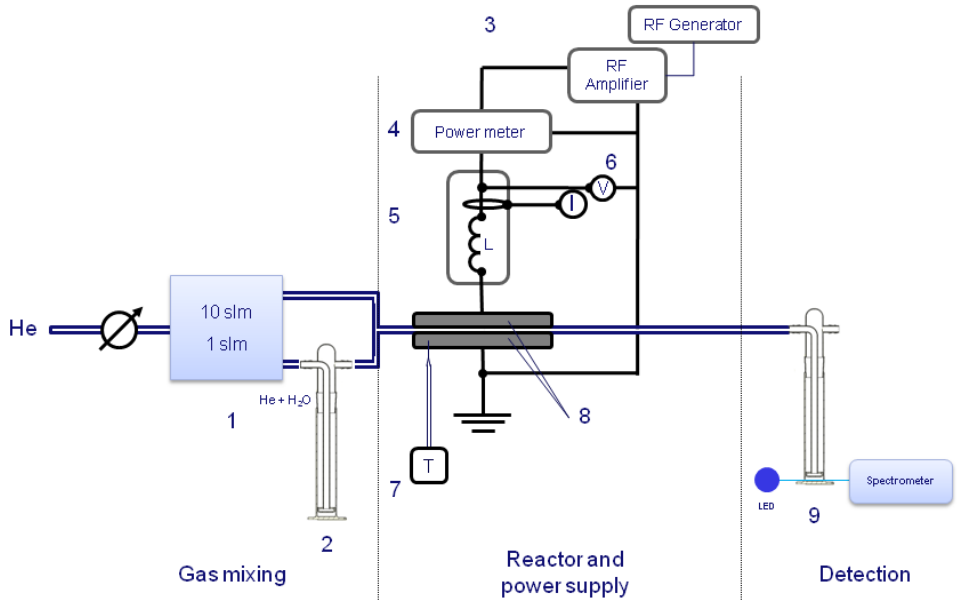

Fig. 1: Schematic overview of the setup - (1) gas feed and mass flow controllers, (2) bubbler to saturate (part of the gas stream) with water vapour, (3) signal generator(s) and RF amplifier (PS), (4) power meter,(5) matching network, (6) voltage probe and current monitor, (7) thermocouple, (8) plasma reactor and (9) bubbler for effluent gas for $\mathrm{H}_{2} \mathrm{O}_{2}$ detection in liquid phase.

\section{Experimental setup and techniques}

\subsection{Plasma reactor}

A schematic description of the experimental setup can be seen in figure 1. A set of mass flow controllers (Brooks 5800, $10 \mathrm{slm}, 1 \mathrm{slm}$ ) are used to control gas flow and admixture concentration to the reactor (see (1)). Helium can be humidified with the help of a water bubbler ( $250 \mathrm{ml}$, Duran) (2), enabling to add up to $3 \%$ water vapor to the helium flow.

The gas is fed to the reactor section of the setup (8). The plasma is a capacitively coupled RF atmospheric pressure glow discharge operating at ambient pressure as investigated in $[16,17]$. In this configuration, the plasma is an APGD which can operate in He with small admixtures of molecular gases such as $\mathrm{H}_{2} \mathrm{O}$. Similar sources have been reported in the literature $[18,19]$. The reactor consists of two stainless steel electrodes $(35 \mathrm{~mm} \times 5 \mathrm{~mm})$ positioned adjacently to form a $1 \mathrm{~mm}$ gap in between. Both ends of the electrodes are rounded off to avoid high local fields and breakdown at the edges of the gap. The RF power is gen- 
erated by amplifying the RF signal generated by signal generator (Power Amplifier E\&I AB-250 and Agilent 33220A $20 \mathrm{MHz}$ Arbitrary Waveform Generator, both (3) in figure 1). A bidirectional coupler with thermal probes (Amplifier Research PM2002) to monitor forward/reflected power is placed between the amplifier and the matching network, which is necessary to efficiently couple power into the reactor. The matching is achieved with a home made coil (5). A current monitor (Pearson 2877) and a voltage probe (Tektronix-P6015A, both (6)) are used to monitor current and voltage (VI) signals in conjunction with an oscilloscope (Agilent Technologies, $250 \mathrm{MHz}, 2 \mathrm{GSa} / \mathrm{s}$ ). The APGD is operated around $13.5 \mathrm{MHz}$, with $0.5 \mathrm{~W}$ to $4 \mathrm{~W}$ dissipated plasma power. The operational frequency may vary within 1 $\mathrm{MHz}$, depending on gas mixture and water concentration to obtain optimal matching conditions.

The discharge can be operated with power-modulation (on-off) of the RF power using an additional signal generator to modulate the amplitude of the RF signal produced by the primary signal generator. The duty cycle of the modulated $(20 \mathrm{kHz})$ signal is varied from $100 \%$ down to $20 \%$, with a precision of around $1 \%$. Below $20 \%$ the discharge becomes increasingly difficult to operate stably and measurements become less reproducible. The effluent gas from the reactor is directed through a bubbler (9) where the $\mathrm{H}_{2} \mathrm{O}_{2}$ is dissolved in a detection liquid, an ammonium metavanadate $\left(\mathrm{NH}_{4} \mathrm{VO}_{3}\right)$ solution. The $\mathrm{H}_{2} \mathrm{O}_{2}$ yield is determined in the detection vessel using the change in absorption due to the reaction of hydrogen peroxide with the ammonium metavanadate in the liquid phase [20]. Combining the dissipated power in the plasma with the concentration of $\mathrm{H}_{2} \mathrm{O}_{2}$ in the liquid volume, the energy efficiency of the reactor can be calculated. The average concentration of $\mathrm{H}_{2} \mathrm{O}_{2}$ in the plasma volume can be calculated from the total flow through the reactor and the obtained concentrations in the detection vessel. The discharge reactor dimensions and its range of operational characteristics are listed in table 2.

Table 2: Dimensions and operational characteristics of the APGD reactor

\begin{tabular}{lll}
\hline electrode length & 35 & $\mathrm{~mm}$ \\
electrode width & 5 & $\mathrm{~mm}$ \\
gap & 1 & $\mathrm{~mm}$ \\
plasma volume (approx) & 175 & $\mathrm{~mm}^{3}$ \\
flow rates & $0.5-4$ & $\mathrm{slm}$ \\
$\begin{array}{l}\text { water concentration } \\
\text { diss. plasma power }\end{array}$ & $0.2-1.6$ & $\%$ of flow \\
$\begin{array}{l}\text { Operation: } \\
\text { continuous RF } \\
\text { modulated RF/frequency }\end{array}$ & $1-3$ & $\mathrm{~W}$ \\
\hline
\end{tabular}

\subsection{Detection of Hydrogen Peroxide}

The detection of low hydrogen peroxide densities in the gas phase using mass spectroscopy is challenging, as the water concentration in the plasma is typically around $10^{4} \mathrm{ppm}$, while expected peroxide densities are in the order of $10 \mathrm{ppm}$ [10], with the fragments of the $\mathrm{H}_{2} \mathrm{O}_{2}$ molecule produced in the ionization source of the mass spectrometer being indistinguishable from those of $\mathrm{H}_{2} \mathrm{O}$. Recent state of the art methods involving infrared multi pass absorption 
as reported by [21] would have been an alternative, but the detection limit is of the order of $1 \mathrm{ppm}$.

Detection of $\mathrm{H}_{2} \mathrm{O}_{2}$ in the liquid phase is well established and, depending on the applied method, can be performed with high sensitivity towards $\mathrm{H}_{2} \mathrm{O}_{2}$ and was thus chosen in this work. A number of well established techniques in chemistry for detecting hydrogen peroxide take advantage of the strong oxidizing properties of $\mathrm{H}_{2} \mathrm{O}_{2}$. Reduction/oxidation titration methods detect concentrations of reaction products, where the reaction is marked visually by a color change of an indicator solution. However, standard methods such as iodometric titration [22] or permanganate titration [23] have a rather low sensitivity and are ideal for higher concentrations of $\mathrm{H}_{2} \mathrm{O}_{2}$. As these are also known to interfere with other active species they have not been considered in this work. Alternatives are spectrophotometric, fluorescence or chemoluminescence methods. A suitable method for low concentrations of $\mathrm{H}_{2} \mathrm{O}_{2}$ uses an ammonium metavanadate $\left(\mathrm{NH}_{4} \mathrm{VO}_{3}\right)$ solution and observe the color change reflecting the oxidation of $\mathrm{V}^{\mathrm{VII}}$ to $\mathrm{V}^{\mathrm{V}}$ at a wavelength of $450 \mathrm{~nm}$ as reported in [20]. The method has been shown to be highly selective to $\mathrm{H}_{2} \mathrm{O}_{2}$ in the presence of many other reactive species such as $\mathrm{Cl}^{-}, \mathrm{NO}_{3}^{-}, \mathrm{Fe}^{3+}$ and $\mathrm{FeO}_{\mathrm{x}}$ with a reported detection limit of $0.143 \mu \mathrm{mol} / \mathrm{l}$. This method was chosen to determine the product yields in the plasma effluent. Possible issues with selectivity are further limited in the present study as the effluent is not in contact with air until after it left the detection vessel. As only helium-water mixtures are considered, $\mathrm{H}_{2} \mathrm{O}_{2}$ is the main long lived species in the far effluent and very few or even no other oxidizing long lived species which could contribute to the oxidation of ammonium metavanadate like ozone are expected to be produced. A comprehensive overview of available methods and their advantages is available in [24].

The effluent from the reactor is bubbled through the detection solution and the peroxovanadium solution gradually turns from bright yellow to crimson with increasing peroxide concentration as more peroxovanadium ions are formed. As a light source for the absorption spectroscopy a blue LED (LED450-06, Roithner LaserTechnik GmbH) is used. The light passing through the absorption cell is detected by a low resolution spectrometer (Avantes AvaSpec-USB2 Fiber Optic Spectrometer).

The concentration (c) of $\mathrm{H}_{2} \mathrm{O}_{2}$ can be determined using the Beer-Lambert Law

$$
I=I_{0} \exp (-\varepsilon c d)
$$

with $\mathrm{I} / \mathrm{I}_{0}$ being the ratio of measured to reference intensity, $d$ the optical absorption path length, $c$ the molar concentration and $\varepsilon$ the molar extinction coefficient of the detection liquid as reported in [20]. For every measurement run, the first obtained spectrum is used as a reference signal. Performing a measurement every minute results in a graph like in figure 2. The slope of a linear fit of these individual measurements is the $\mathrm{H}_{2} \mathrm{O}_{2}$ yield in $\mathrm{mol} / \mathrm{l} \cdot \mathrm{min}$ in the detection volume. Combined with the measured plasma power the energy efficiency $(\eta)$ in units of $[\mathrm{g} / \mathrm{kWh}]$ can be calculated. All measurements in this work have been performed using this method, and the actual $\mathrm{mmol} / \mathrm{l}$ are representing the concentration per sample volume of $40 \mathrm{ml} \pm 0.1 \mathrm{ml}$. Transforming this concentration into molar densities and considering the flow through the system allows gas phase (volume) densities of hydrogen peroxide $\left(n_{\mathrm{H}_{2} \mathrm{O}_{2}}\right)$ to be calculated.

The plasma was switched on at least 15 min before starting $\mathrm{H}_{2} \mathrm{O}_{2}$ measurements to allow the setup to reach operational temperatures, to stabilize the discharge and to avoid thermal drift of the setup which could have an influence on the power consumption.

Detection efficiency Possible influences on the detection efficiency of this method were scrutinized to ensure the reproducibility of results. The LED was chosen as light source 


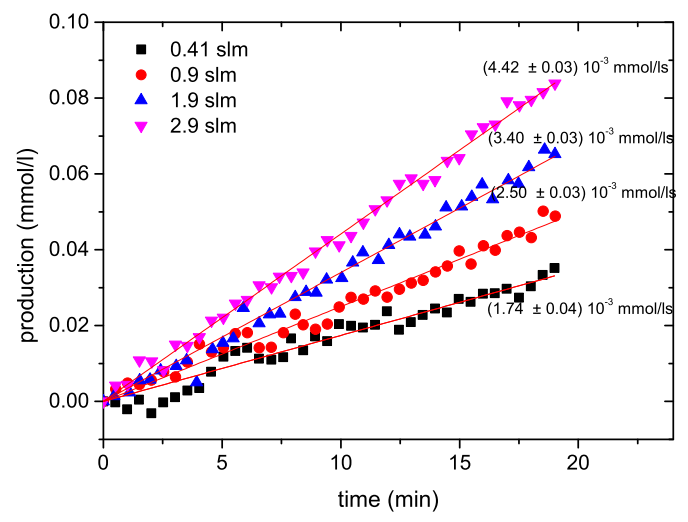

Fig. 2: Example of peroxide concentration measurements for varying flow rates in solution in the detection bubbler. The plasma dissipated power and water concentration is fixed at $2.7 \pm 0.2 \mathrm{~W}$ and $0.47 \%$ respectively.

because of its stability in time. The LED fluctuates on average below $0.3 \%$ in its intensity (below $0.2 \%$ during one set of measurements), while a halogen lamp can fluctuate by as much as $6 \%$. This improves the signal to noise ratio, allowing for significantly shorter integration times and higher reproducibility.

Gas mixing in a bubbler such as the one used in the detection vessel was also considered. The efficiency of the gas-to-liquid phase transfer depends on the surface to volume ratio of the gas bubbles and the time these spend rising through the liquid column above the sieve. In order to establish whether there are any losses of $\mathrm{H}_{2} \mathrm{O}_{2}$ molecules which did not dissolve from the gas phase, two recipients were placed in series and the concentration of $\mathrm{H}_{2} \mathrm{O}_{2}$ was measured in both vessels simultaneously with the same method. $\mathrm{No}_{2} \mathrm{O}_{2}$ signal was detected in the second bubbler, even after a measurement time 4-5 times longer than the usual measurement times.

The reproducibility of the measurements during a single measurement series is within $10 \%$. The day-day reproducibility of the measurement is within a factor 2 . The inaccuracies are determined by the discharge conditions and not by the detection methods. The experimental accuracies presented in the $\mathrm{H}_{2} \mathrm{O}_{2}$ concentrations are obtained by at least 3 repetitive measurements.

Using the $\mathrm{H}_{2} \mathrm{O}_{2}$ measurements to calculate the $\mathrm{H}_{2} \mathrm{O}_{2}$ density in the plasma implicitly includes the assumption that no $\mathrm{H}_{2} \mathrm{O}_{2}$ is lost between plasma and detection in the liquid phase. However, the dissociation of $\mathrm{H}_{2} \mathrm{O}_{2}$ on surfaces is a known issue in surface chemistry and has been studied on various surfaces [25,26]. Losses for densities of $40000 \mathrm{ppm} \mathrm{H}_{2} \mathrm{O}_{2}$ (evaporated pure hydrogen peroxide water mixture) on Pyrex at $488 \mathrm{~K}$ have been reported to be below $0.1 \%$ in [26]. Rescaled to the densities in our detection system and considering the surface area of the system, this loss is negligible in comparison to the total concentration. As $\mathrm{H}_{2} \mathrm{O}_{2}$ is readily soluble in water, water droplets on the tubing could lead to a loss of $\mathrm{H}_{2} \mathrm{O}_{2}$. The experiments reported in this study have been performed at a relative humidify less than $50 \%$ to prevent condensation of the water vapor on tubing. Therefore, the calculated values of $n_{\mathrm{H}_{2} \mathrm{O}_{2}}$ can be considered to accurately reflect the $\mathrm{H}_{2} \mathrm{O}_{2}$ density in the reactor. 


\subsection{Power measurements}

Both reflected and forward applied power are measured in a bidirectional coupler with thermal probes between power amplifier and matching box, see in figure 1. To calculate the power dissipated by the plasma alone, it is necessary to correct the applied power $\left(P^{\text {applied }}=P^{\text {forward }}-P^{\text {reflected }}\right)$ going into the matching box and the reactor for the losses in the matching box. The temperature of the coil was measured for both on and off cases, showing no significant difference in temperature between plasma on and off at a given current, allowing us to assume the same losses occur in the matching box at a given current as shown previously in a similar system [27].

Thus, the plasma dissipated power $(P)$ can be obtained as

$$
P^{\text {plasma }}\left(I_{r m s}\right)=P^{\text {applied }}\left(I_{r m s}\right)-P^{\text {match }}\left(I_{r m s}\right)
$$

for which $P^{\text {match }}\left(I_{r m s}\right)$ represents the losses in the coil. This motivates the calculations at given currents. With all losses established as a function of the applied RMS current, it was possible to set and monitor specific dissipated plasma powers. All powers presented in this report are the plasma dissipated power.

To illustrate the power measurements, figure 3 depicts the applied power to the system $P^{\text {applied }}$ when plasma is on and off as a function of the current.

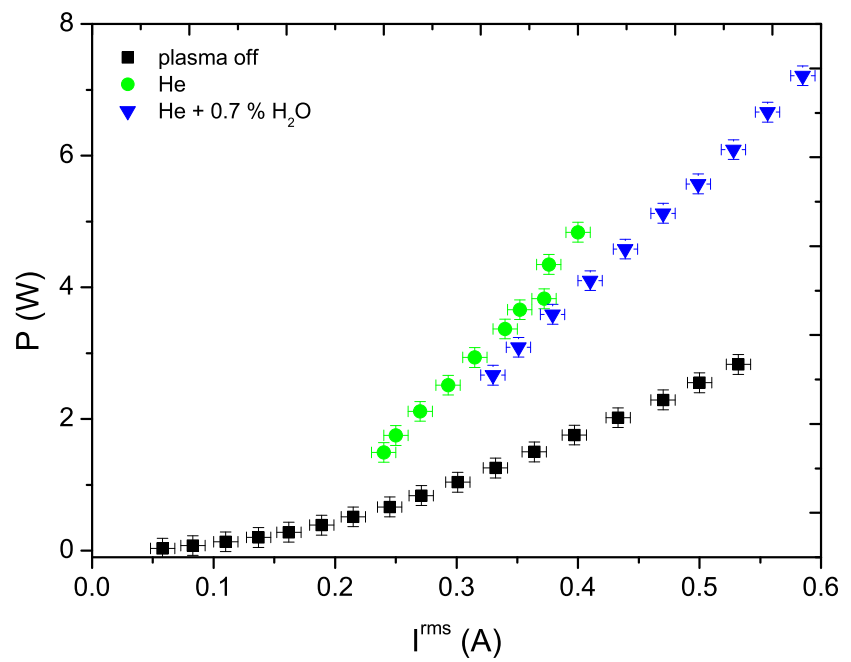

Fig. 3: Applied powers as a function of the RMS current for a plasma in $\mathrm{He}$ and $\mathrm{He}$ with $0.7 \%$ water.

\subsection{Gas temperature determination}

Two methods have been used to determine the gas temperature: optical emission spectroscopy using the rotational bands of $\mathrm{N}_{2}(\mathrm{C}-\mathrm{B})$ at $337 \mathrm{~nm}$ and using a thermocouple (Fluke 
Table 3: Reaction rates used in this study that differ from those of our previous work [10, 29].

\begin{tabular}{llll}
\hline Reaction & Rate $\left(\mathrm{cm}^{3} \mathrm{~s}^{-1}\right)$ & Ref. & Rate / Old rate [10] \\
\hline & & & $T_{g}=350 \mathrm{~K}$ \\
$\mathrm{OH}+\mathrm{H}_{2} \mathrm{O}_{2} \rightarrow \mathrm{H}_{2} \mathrm{O}+\mathrm{HO}_{2}$ & $2.88 \cdot 10^{-12} \exp \left(-156.3 / T_{g}\right)$ & {$[30]$} & 0.91 \\
$\mathrm{OH}+\mathrm{OH}+\mathrm{He} \rightarrow \mathrm{H}_{2} \mathrm{O}_{2}+\mathrm{He}$ & $3.7 \cdot 10^{-43}\left(T_{g} / 300\right)^{-0.8}$ & {$[31,32]$} & 0.47 \\
$\mathrm{OH}+\mathrm{HO}_{2} \rightarrow \mathrm{O}_{2}+\mathrm{H}_{2} \mathrm{O}$ & $2.61 \cdot 10^{-11} \exp \left(372.85 / T_{g}\right)$ & {$[30]$} & 1.23 \\
$\mathrm{H}+\mathrm{HO}_{2} \rightarrow \mathrm{OH}+\mathrm{OH}$ & $2.93 \cdot 10^{-13} T_{g}^{0.9} \exp \left(36.08 / T_{g}\right)$ & {$[30]$} & 0.78 \\
$\mathrm{H}+\mathrm{H}_{2} \mathrm{O}_{2} \rightarrow \mathrm{H}_{2}+\mathrm{HO}_{2}$ & $2.61 \cdot 10^{-11} \exp \left(-3162 / T_{g}\right)$ & {$[30]$} & 3.34 \\
$\mathrm{O}+\mathrm{H}_{2} \mathrm{O}_{2} \rightarrow \mathrm{OH}+\mathrm{HO}_{2}$ & $1.11 \cdot 10^{-12} \exp \left(-1943.6 / T_{g}\right)$ & {$[30]$} & 0.002 \\
$\mathrm{e}+\mathrm{H}_{2} \mathrm{O}_{2} \rightarrow \mathrm{OH}^{-}+\mathrm{OH}$ & $f\left(T_{e}\right)$ & {$[33]$} & 2.57
\end{tabular}

80BK-A type K) inserted into the grounded electrode of the reactor (see figure 1). To obtain the emission spectra, an optical fiber was used to collect the emission from the plasma and coupled to a spectrometer (Jobin Yvon HT-1000 monochromator). $0.2 \% \mathrm{~N}_{2}$ is added to the gas flow to enable us to measure the $\mathrm{N}_{2}(\mathrm{C}-\mathrm{B})(0-0)$ rotational emission spectrum. The obtained emission spectra were compared to synthetic spectra from Specair [28] using an experimentally obtained slit function (by measuring the broadening of a $\mathrm{Hg} \mathrm{I}$ line obtained at $312.56 \mathrm{~nm}$ from a low pressure mercury lamp). In figure 4 , a typical spectrum of (0-0) vibrational band of the second positive system of nitrogen is shown with 3 different simulated spectra. Even though the spectra seem to suggest a gas temperature of $360 \mathrm{~K}$ with a precision of around $\pm 10 \mathrm{~K}$, the slightest variations in the slit function, the signal to noise ratio and background subtraction enlarge this error to $\pm 25 \mathrm{~K}$.

As the changes in gas temperature of the plasma in this work are also in the order of 30 to $60 \mathrm{~K}$, this method provides only little information on effective temperature variations in our case. Clear differences between various settings such as low power, low water concentration and high power, high water concentration mixtures could be expected and should be detected reliably.

Thus the alternative method of using a thermocouple has been considered. A thermocouple (Fluke 80BK-A ) was inserted into the grounded electrode of the reactor. The reactor electrode reached its steady state $T_{\text {gas }}$ within $\sim 50 \mathrm{~min}$, with fluctuations of around $\pm 0.2 \mathrm{~K}$. The reproducibility of these measurements are in the range of $2-7 \mathrm{~K}$. The thermocouple calibration was validated using boiling water and water ice. A comparison between both methods yields a good correspondence within the experimental accuracy with an off set for the temperature obtained by emission of $10 \mathrm{~K}$. In this work thermocouple measurements are used because they allow easy, accurate and real time monitoring of the gas temperature.

\section{Description of global kinetics model and 1-D fluid model}

In this section we describe the three computational models used in this work. The models are used to provide insights into the chemical pathways likely to be governing these discharges and computational results will be compared to asses the validity of the computational models and reaction sets used. The first model is the global model published by Liu et al [10]. This is a zero dimensional model that incorporates a large set of chemical reactions. Although qualitative agreement with experimental observations has been reported, quantitative discrepancies between experimental and computational results observed during this study have led to an improved model. Namely, vibrational and rotational excitation is considered in the 
new global model, the input power coupled to ions is also taken into account and electrode and radial losses are refined according to [29]. In addition some reaction rates have been updated as shown in table 3. This second model has a better quantitative agreement with experimental observations (see further) although the agreement is still not completely satisfactory. Both these models assume that energy is deposited uniformly across the discharge, and that as a result there is no spatial variation of the electron mean energy.

Although this intrinsic approximation of global models is often reasonable for low pressure discharges dominated by non-local kinetics, atmospheric pressure plasmas are highly non-uniform and energy deposition and dissipation vary significantly across the discharge and during the RF cycle (see figure 5 in which sheath regions can clearly be observed). Therefore, better quantitative agreement is expected if the spatio-temporal variations are taken into account. These are incorporated in the third model, a 1-dimensional fluid model. The fluid model is based on the model used in references [11,29] and briefly it solves the continuity equation for each plasma species, the electron energy equation and Poisson's equation. Due to the large collisionality of atmospheric pressure plasmas $\left(v>>\omega_{r} f\right.$ where $v$ is the neutral collision frequency and $\omega_{r} f$ the angular driving frequency), the particle inertia is neglected and the drift-diffusion approximation is used to determine the mean velocity for each species. A few modifications have been made to the model used in [11] for this study:

1. Incorporation of rotational and vibrational excitation of water molecules in the electron energy balance equation. The reaction rates for these reactions are calculated as a function of the mean electron energy using Bolsig+ [34] and the cross section data reported in [35]. This is an important modification as approximately $22 \%$ of the electron energy is lost via rotational and vibrational excitation.

2. $\mathrm{OH}$ and $\mathrm{H}_{2} \mathrm{O}_{2}$ are assumed to be lost on the walls/electrodes with a probability of 1 and 0.4 , respectively [26]. Although it is difficult to obtain reliable data for the loss probability, this is not critical in determining the steady state equilibrium as the main loss mechanisms for both $\mathrm{OH}$ and $\mathrm{H}_{2} \mathrm{O}_{2}$ are volume reactions. Therefore although these losses reduce the density of the $\mathrm{OH}$ and $\mathrm{H}_{2} \mathrm{O}_{2}$ near the electrodes, the average density is only marginally affected.

3. Reaction rates for a number of reactions (see table 3 ) have been recalculated using Bolsig+ [34] and the cross section data reported in the NIST Chemical Kinetics Database [30] and reference [33].

\section{Experimental results}

In figures 6, 7, 8 and 9 energy efficiencies for $\mathrm{H}_{2} \mathrm{O}_{2}$ production and corresponding gas phase concentrations are shown as a function of water concentration, gas flow, plasma dissipated power and duty cycle of the RF power modulation. While the $\mathrm{H}_{2} \mathrm{O}_{2}$ production rises with increasing water concentration, flow and power, the production efficiency increases with water concentration and flow and remains constant in the investigated power range. The power modulation has little effect on both the $\mathrm{H}_{2} \mathrm{O}_{2}$ concentration and production efficiency.

The yield seems proportional to the water concentration in the plasma for low water concentrations. This result concurs with results reported in [10], where an increase in water concentration was linked to increasing species densities of $\mathrm{OH}, \mathrm{H}_{2} \mathrm{O}_{2}$ and other species, albeit at much lower concentrations. As shown by recent measurements by Bruggeman et al. [36] the $\mathrm{OH}$ density in this type of discharges scales with the square root of the $\mathrm{H}_{2} \mathrm{O}$ density (at least up to $1 \%$ water). The main source for forming $\mathrm{H}_{2} \mathrm{O}_{2}$ in non-equilibrium 
cold $(300 \mathrm{~K}$ to $400 \mathrm{~K})$ atmospheric pressure water-containing plasmas is via the three body recombination of the hydroxyl radical to form hydrogen peroxide $\mathrm{OH}+\mathrm{OH}+\mathrm{M} \rightarrow \mathrm{H}_{2} \mathrm{O}_{2}$ $+\mathrm{M}[9,10]$. In first approximation, the $\mathrm{H}_{2} \mathrm{O}_{2}$ yield will scale linearly with increasing $\mathrm{H}_{2} \mathrm{O}$ concentration, as the square of the $\mathrm{OH}$ density scales linearly with the $\mathrm{H}_{2} \mathrm{O}$ [36]. As for larger $\mathrm{OH}$ concentrations, the $\mathrm{OH}$ becomes important in the destruction of $\mathrm{H}_{2} \mathrm{O}_{2}$ and the linear correlation breaks down at higher water concentrations. In addition strong changes in the electron density and temperature at higher water concentrations could cause a deviation from the reported $\mathrm{OH}$ density dependence in [36].

Figure 7 indicates that the $\mathrm{H}_{2} \mathrm{O}_{2}$ production increases linearly with power, hence $\eta$ is constant. Below $1 \mathrm{~W}$ the APGD becomes increasingly unstable and no longer covers the entire length of the discharge gap before it extinguishes entirely. Gas temperature could be suspected to be of importance, however the biggest temperature variation of all cases (corresponding to the variation of total flow) is about $30 \mathrm{~K}$. Using thermal dissociation reaction rates of $\mathrm{H}_{2} \mathrm{O}_{2}$ at even $500 \mathrm{~K}$ shows that these rates are several orders of magnitude slower compared to other loss mechanisms (see also further).

\subsection{Varying the flow}

The gas flow was varied between between 0.5 and 4 slm at $2.7 \mathrm{~W}$ constant dissipated power and $0.47 \%$ water concentration (figure 8 ). Temperature measurements where performed in conjunction with measuring the peroxide yield and efficiency. The change in flow causes a factor 10 increase in the $\mathrm{H}_{2} \mathrm{O}_{2}$ density and a corresponding boost in production efficiency. The main effect which leads to the boost in $\mathrm{H}_{2} \mathrm{O}_{2}$ production is related to the change in residence time from $15 \mathrm{~ms}$ to around $4 \mathrm{~ms}$ and not the variation of $T_{\text {gas }}$.

To explain these observations made by varying the flow, changes to the balance of production and destruction processes of $\mathrm{H}_{2} \mathrm{O}_{2}$ in the plasma at different flows have to be considered. This balance can be written as

$$
n_{O H}^{2} \cdot n_{M} \cdot k_{1} V=\sum_{i=1}^{k} n_{i} \cdot n_{H_{2} O_{2}} \cdot k_{i} V+\Phi n_{H_{2} O_{2}}+\Gamma_{\text {surface }} A
$$

where the production equals bulk losses, losses due to gas flow $\Phi\left(\mathrm{cm}^{3} / \mathrm{s}\right)$, and surface reactions with a flux term $\Gamma_{\text {surface }}$ and the surface area of the reactor $A$. As mentioned above the main source for forming $\mathrm{H}_{2} \mathrm{O}_{2}$ in water containing atmospheric pressure plasmas is via the three body recombination of the hydroxyl radical with reaction rate $k_{1}$. The bulk $\mathrm{H}_{2} \mathrm{O}_{2}$ losses are due to chemical reactions with species $i$ with corresponding density $\left(n_{i}\right)$ and reaction rate $\left(k_{i}\right)$. $V$ stands for the volume of the reactor.

Within the reactor, the plasma is in contact with the electrodes and molecules can be lost to the metal surfaces and as the loss to metal is more efficient compared to quartz glass, it is considered in the balance. The net flux of $\mathrm{H}_{2} \mathrm{O}_{2}$ molecules to a surface can be estimated with the relation

$$
\Gamma_{\text {surface }}=\frac{1}{4} \gamma \alpha n_{\mathrm{H}_{2} \mathrm{O}_{2}} \bar{v}_{t h}=\gamma \alpha n_{\mathrm{H}_{2} \mathrm{O}_{2}} \sqrt{\frac{k_{B} T}{2 \pi M_{\mathrm{H}_{2} \mathrm{O}_{2}}}}
$$

using $n_{H_{2} \mathrm{O}_{2}}$ for the $\mathrm{H}_{2} \mathrm{O}_{2}$ density, the reaction probability $\gamma$, the average thermal velocity $\overline{\mathrm{v}}_{\mathrm{th}}, \alpha$ the ratio between the surface and average density of $\mathrm{H}_{2} \mathrm{O}_{2}$ which is approximately 50 as estimated from the 1-D fluid model, the mass $M_{\mathrm{H}_{2} \mathrm{O}_{2}}$ of 34 amu for $\mathrm{H}_{2} \mathrm{O}_{2}$ and the 
Boltzmann constant $k_{B} \cdot \gamma$ for the condition presented in the case of a study concerning $\mathrm{H}_{2} \mathrm{O}_{2}$ on various surfaces [26] can be estimated to about 0.4.

To estimate the losses of $\mathrm{H}_{2} \mathrm{O}_{2}$ in the bulk, several reactions have to be taken into account. One of main contributors to bulk losses of $\mathrm{H}_{2} \mathrm{O}_{2}$ is the reaction $\mathrm{OH}+\mathrm{H}_{2} \mathrm{O}_{2} \rightarrow \mathrm{H}_{2} \mathrm{O}$ $+\mathrm{HO}_{2}[9,37,38]$, while similar loss reactions with $\mathrm{O}$ and $\mathrm{H}$ radicals exist. In addition, electrons can dissociate $\mathrm{H}_{2} \mathrm{O}_{2}$. Clearly, radical species densities and the electron density are both of key importance for this balance. To find an approximation for the electron density, recent results of [39] for a RF micro atmospheric plasma jet investigating atomic oxygen formation have been reported in the order of $n_{e}=10^{11} \mathrm{~cm}^{-3}$ for the power density in our case. For the case of $\mathrm{He}-\mathrm{H}_{2} \mathrm{O}$, the results of the $1 \mathrm{D}$ model (see further) yields $n_{e}=5 \cdot 10^{10} \mathrm{~cm}^{-3}$. The combined rate for both electron attachment and dissociative attachment of $\mathrm{H}_{2} \mathrm{O}_{2}$ has been calculated from the total cross section reported in [33], for which a $T_{e}$ of $3 \mathrm{eV}$ was assumed $\left(4.2710^{-10} \mathrm{~cm}^{3} / \mathrm{s}\right)$. Rates for electron impact dissociation reported in [40] are obtained for a specific discharge conditions and estimated from known $\mathrm{O}_{2}$ dissociation rates and might thus not very be very accurate. In view of lack of other data, we used this rate in this analytical estimate to calculate the electron induced loses. As for other losses involving reactions of $\mathrm{H}$ and $\mathrm{O}$ with $\mathrm{H}_{2} \mathrm{O}_{2}, \mathrm{H}$ and $\mathrm{O}$ densities reported in [10] (see also further) indicate that these are clearly smaller than the $\mathrm{OH}$ density and the rates are smaller. Thus $\mathrm{H}_{2} \mathrm{O}_{2}$ losses induced by $\mathrm{H}$ and $\mathrm{O}$ are negligible compared to the $\mathrm{OH}$ induced losses.

Estimates of the flow losses due to high gas flows through the reactor are also considered. An estimate of photo-dissociation losses of hydrogen peroxide due to UV photons [41] from $\mathrm{OH}(\mathrm{A})$ indicates that these are expected not to significantly contribute to the destruction of $\mathrm{H}_{2} \mathrm{O}_{2}$ in the present experiment.

Considering the above, the calculated balance is shown in figure10. In this figure, the measured $\mathrm{H}_{2} \mathrm{O}_{2}$ density and gas temperature are used and $\gamma=0.4$ and $n_{e}=5 \cdot 10^{11} \mathrm{~cm}^{-3}$ is assumed. The $\mathrm{OH}$ density is obtained by imposing that the balance equation 1 is satisfied. It can be concluded that the dominant loss mechanisms in the case presented here are $\mathrm{OH}$ induced losses in the bulk and electron induced losses. The obtained $n_{O H}=6 \cdot 10^{13} \mathrm{~cm}^{-3}$ is smaller than the value for similar $\mathrm{H}_{2} \mathrm{O}_{2}$ concentration and power densities as obtained in [36] ( $n_{O H}=3 \cdot 10^{14} \mathrm{~cm}^{-3}$, when lambda doubling is considered in the absorption measurement). At low flow rates, however, it is not possible to find an $\mathrm{OH}$ density that satisfies the balance equation 1 . This is attributed to higher impurities at low flow rates mainly consisting of air. These impurities not considered in the balance equation lead to higher $\mathrm{H}_{2} \mathrm{O}_{2}$ losses and could significantly influence the reaction chemistry in the discharge. If the gradient of $\mathrm{H}_{2} \mathrm{O}_{2}$ is not considered for the wall losses, the wall losses become one of the dominant losses and the corresponding fitted $\mathrm{OH}$ density is $1.5 \cdot 10^{14} \mathrm{~cm}^{-3}$ instead of $6 \cdot 10^{13} \mathrm{~cm}^{-3}$. The $\mathrm{OH}$ density determination with the balance equation yields values with reasonable correspondence to the experimentally about $\mathrm{OH}$ density in [36].

Finally, to check experimentally if the electron losses are properly accounted for, power modulating the discharge was considered as losses depending on $n_{e}$ are expected to strongly vary with the duty cycle.

\subsection{Power modulation}

In power modulated operational mode, the duty cycle represents the time in percent for which the APGD is on. Varying the water concentration and the power exhibit the same behavior as in the continuous case (results not shown). The duty cycle of a time modulated plasma at $20 \mathrm{kHz}$ was varied in figure 9, where the instantaneous power during the plasma on 
Table 4: Comparison between experimental and computational results: mean densities for a discharge across a $1 \mathrm{~mm}$ gap at $2.78 \mathrm{~W}\left(1.59 \mathrm{Wcm}^{-2}\right), 13.5 \mathrm{MHz}, 0.47 \% \mathrm{H}_{2} \mathrm{O}, 2 \mathrm{slm}$ flow, $T_{g}=348 \mathrm{~K}$. ${ }^{+}$The experimental obtained $\mathrm{OH}$ density is obtained by the analytical balance in previous section.

\begin{tabular}{lllll}
\hline & experimental & global model [10] & Improved global model & 1 D fluid model \\
\hline$\left\langle n_{e}\right\rangle\left(\mathrm{cm}^{-3}\right)$ & - & $6.9 \cdot 10^{10}$ & $2.48 \cdot 10^{10}$ & $5.2 \cdot 10^{10}$ \\
$\left\langle n_{H 2 O 2}\right\rangle\left(\mathrm{cm}^{-3}\right)$ & $1.3 \cdot 10^{14}$ & $1.1 \cdot 10^{15}$ & $0.98 \cdot 10^{15}$ & $3.2 \cdot 10^{14}$ \\
$\left\langle n_{O H}\right\rangle\left(\mathrm{cm}^{-3}\right)$ & $0.7-1.5^{+} \cdot 10^{14}$ & $2.24 \cdot 10^{14}$ & $2.95 \cdot 10^{14}$ & $2.2 \cdot 10^{14}$ \\
$\frac{\left\langle n_{H 2 O 2}\right\rangle}{\left\langle n_{O H}\right\rangle}\left(\mathrm{cm}^{-3}\right)$ & $0.9-1.9$ & 5.6 & 3.32 & 1.5 \\
$T_{e}(\mathrm{eV})$ & - & 3.96 & 2.6 & 2.4 \\
\hline
\end{tabular}

phase was kept constant and thus the average plasma power decreased with decreasing duty cycle. The gas temperature could be expected to vary greatly in comparison to the continuous case, but the observed change is similar to the continuous case. However, this only represents an average $T_{g a s}$ as it is obtained inside of the electrode and cannot be expected to properly reflect the actual gas temperature of the modulated plasma.

The balance of losses and production (figure 11) has been performed similarly to the flow dependence case using the same reaction rates, species densities and with the assumption of $\gamma=0.4$. As expected, the electron induced losses significantly drop at shorter duty cycles as electron dissociation will mainly occur during the plasma on time. Assuming $\mathrm{OH}+\mathrm{OH}+\mathrm{M} \rightarrow$ products, as the main loss mechanism of $\mathrm{OH}$ and for an initial density $\mathrm{n}_{O H} \approx 1 \cdot 10^{14} \mathrm{~cm}^{-3}$, the $\mathrm{OH}$ density is expected to decrease about $5 \%$ during the longest plasma off phase. This indicates that the decay time of $\mathrm{OH}$ is significantly longer than the plasma off time and the $\mathrm{OH}$ density was assumed to be constant over time in the balance equation.

The balance as shown in figure 11 shows that electron induced losses cannot be the dominant loss mechanism and that the exact value of $n_{e}$ in this case does not significantly influence the balance of production and destruction. A good fitting for the $100 \%$ and $80 \%$ can be obtained for $n_{O H}=4 \cdot 10^{13} \mathrm{~cm}^{-3}$, which is smaller than in the flow case, as expected due to the smaller average plasma power. A small reduction of the $\mathrm{OH}$ density and larger fluctuations on the plasma power for short duty cycles could explain the discrepancy between the observed experiments and the balance estimate for small duty cycles. This may be enhanced by the increasing importance of the transient start-up phenomena for the power modulation with smaller duty cycle. In addition, the discrepancy at small duty cycles could also be due to an overestimate of the electron induced losses in the balance, which strongly reduce for the smallest duty cycles.

It can thus be concluded that $\mathrm{OH}$ bulk losses are an important loss mechanisms of $\mathrm{H}_{2} \mathrm{O}_{2}$ through reaction $\mathrm{OH}+\mathrm{H}_{2} \mathrm{O}_{2}+\mathrm{M} \rightarrow \mathrm{H}_{2} \mathrm{O}+\mathrm{HO}_{2}$ and that the electron induced losses considered might be an overestimate compared to the actual losses in the experiment.

\section{Comparison between numerical models and experimental results}

Computational results of the three models (global model, improved global model and 1-D fluid model described above) are compared with experiment data in table 4. An atmospheric pressure discharge maintained across a $1 \mathrm{~mm}$ gap at $2.78 \mathrm{~W}\left(1.59 \mathrm{Wcm}^{-2}\right), 13.5 \mathrm{MHz}$, $0.47 \% \mathrm{H}_{2} \mathrm{O}, 2 \mathrm{slm}$ flow, $T_{g}=348 \mathrm{~K}$ is considered for the comparison. The gas temperature 
Table 5: Generation and loss mechanisms of $\mathrm{H}_{2} \mathrm{O}_{2}$ for a discharge across a $1 \mathrm{~mm}$ gap at 2.78 $\mathrm{W}\left(1.59 \mathrm{Wcm}^{-2}\right), 13.5 \mathrm{MHz}, 0.47 \% \mathrm{H}_{2} \mathrm{O}, 2 \mathrm{slm}$ flow, $T_{g}=348 \mathrm{~K}$.

\begin{tabular}{ll}
\hline & percentage of total generation \\
\hline generation mechanisms & \\
$\mathrm{OH}+\mathrm{OH}+\mathrm{M} \rightarrow \mathrm{H}_{2} \mathrm{O}_{2}+\mathrm{M}$ & $99.60 \%$ \\
$\mathrm{HO}_{2}+\mathrm{HO}_{2} \rightarrow \mathrm{H}_{2} \mathrm{O}_{2}+\mathrm{O}_{2}$ & $0.40 \%$ \\
\hline Loss mechanism & \\
$\mathrm{OH}+\mathrm{H}_{2} \mathrm{O}_{2} \rightarrow \mathrm{H}_{2} \mathrm{O}+\mathrm{HO}_{2}$ & $42.92 \%$ \\
$\mathrm{Radial} \mathrm{loss}$ & $25.98 \%$ \\
Electrode loss & $11.78 \%$ \\
$\mathrm{e}+\mathrm{H}_{2} \mathrm{O}_{2} \rightarrow \mathrm{OH}+\mathrm{OH}+\mathrm{e}$ & $11.44 \%$ \\
$\mathrm{H}+\mathrm{H}_{2} \mathrm{O}_{2} \rightarrow \mathrm{H} \mathrm{H}_{2} \mathrm{O}+\mathrm{OH}$ & $3.55 \%$ \\
$e+\mathrm{H}_{2} \mathrm{O}_{2} \rightarrow \mathrm{OH}+\mathrm{OH}^{-}$ & $2.90 \%$ \\
$\mathrm{e}+\mathrm{H}_{2} \mathrm{O}_{2} \rightarrow \mathrm{H}_{2} \mathrm{O}+\mathrm{O}^{-}$ & $0.57 \%$ \\
Other & $0.86 \%$ \\
\hline
\end{tabular}

was measured in the experiments as $348 \mathrm{~K}$ and this value was used for the simulations. The quantitative agreement between the experimental and computational results increases with the refinement of the model and although deviations between experimental measurements and computational predictions remain, quantitative agreement for the fluid model is within the uncertainty in reaction rates and experimental accuracy. Nonetheless, some conclusions can be drawn from this exercise. The comparison evidences that vibrational and rotational excitation of water molecules is important in the energy balance of these discharges and indeed they should be accounted for if quantitative predictions are sought. Despite the low energy exchanged per collision in these processes, the large collisionality of atmospheric pressure plasmas results in a large net electron energy loss. $15 \%$ of the input power is spent in accelerating ions, and of the remaining $85 \%$ delivered to the electrons, $55 \%$ is dissipated via elastic collisions and $22 \%$ via vibrational and rotational excitation of water molecules.

The power delivered to the ions is calculated from the simulations as the space integral of the total ionic current density times the electric field $\left(J_{i o n s} E\right)$ over an RF period and it accounts for both losses in the sheaths and in the bulk, the later becoming significant in electronegative atmospheric pressure discharges (see also ref. [29]). Similarly the power coupled to the electrons can be determined by integrating the product of the electron current density times the electric field $\left(J_{e} E\right)$. Furthermore, the electron energy lost in a particular channel (e.g. elastic collision, vibrational excitation, etc.) is determined by integrating over the discharge gap and an RF period the reaction rate of that particular process times the electron energy lost per reaction; data readily available in the simulations.

Simulation results can also be analyzed to identify the chemical reactions that lead to the formation and destruction of key plasma species. Table 5 and Table 6 show the main processes leading to the generation and loss of $\mathrm{H}_{2} \mathrm{O}_{2}$ and $\mathrm{OH}$, respectively. Note that these results confirm the analytical estimate made in the previous section. It is worth mentioning that despite the quantitative differences among the different models shown in table 4, the same main chemical pathways (although with different quantitative contribution) are identified by the three computational models, justifying the use of global models for qualitative chemical analysis. However, there is a significant quantitative difference between the global and fluid models. These are attributed to the use of a space-averaged electron temperature in the global model, which contrasts with the spatial evolution of the mean electron energy in the fluid simulation (see figure 5). 
Table 6: Generation and loss mechanisms of $\mathrm{OH}$ for a discharge across a $1 \mathrm{~mm}$ gap at 2.78 $\mathrm{W}\left(1.59 \mathrm{Wcm}^{-2}\right), 13.5 \mathrm{MHz}, 0.47 \% \mathrm{H}_{2} \mathrm{O}, 2 \mathrm{slm}$ flow, $T_{g}=348 \mathrm{~K}$.

\begin{tabular}{|c|c|}
\hline & percentage of total generation \\
\hline \multicolumn{2}{|l|}{ generation mechanisms } \\
\hline $\mathrm{e}+\mathrm{H}_{2} \mathrm{O} \rightarrow \mathrm{H}+\mathrm{OH}+\mathrm{e}$ & $43.99 \%$ \\
\hline $\mathrm{H}+\mathrm{HO}_{2} \rightarrow \mathrm{OH}+\mathrm{OH}$ & $13.13 \%$ \\
\hline $\mathrm{H}_{2} \mathrm{O}^{+}+\mathrm{H}_{2} \mathrm{O} \rightarrow \mathrm{H}_{3} \mathrm{O}^{+}+\mathrm{OH}$ & $12.21 \%$ \\
\hline $\mathrm{e}+\mathrm{H}_{2} \mathrm{O} \rightarrow \mathrm{OH}+\mathrm{H}^{-}$ & $8.96 \%$ \\
\hline $\mathrm{O}\left({ }^{1} \mathrm{D}\right)+\mathrm{H}_{2} \mathrm{O} \rightarrow \mathrm{OH}+\mathrm{OH}$ & $6.42 \%$ \\
\hline $\mathrm{OH}(\mathrm{A})+\mathrm{H}_{2} \mathrm{O} \rightarrow \mathrm{H}_{2} \mathrm{O}+\mathrm{OH}$ & $6.36 \%$ \\
\hline $\mathrm{e}+\mathrm{H}_{2} \mathrm{O}_{2} \rightarrow \mathrm{OH}+\mathrm{OH}+\mathrm{e}$ & $4.42 \%$ \\
\hline $\mathrm{OH}^{+}+\mathrm{H}_{2} \mathrm{O} \rightarrow \mathrm{H}_{2} \mathrm{O}^{+}+\mathrm{HO}$ & $0.98 \%$ \\
\hline Others & $3.62 \%$ \\
\hline \multicolumn{2}{|l|}{ Loss mechanism } \\
\hline $\mathrm{OH}+\mathrm{OH}+\mathrm{M} \rightarrow \mathrm{H}_{2} \mathrm{O}_{2}+\mathrm{M}$ & $38.44 \%$ \\
\hline $\mathrm{He}+\mathrm{H}+\mathrm{OH} \rightarrow \mathrm{He}+\mathrm{H}_{2} \mathrm{O}$ & $11.73 \%$ \\
\hline Electrode loss & $10.89 \%$ \\
\hline $\mathrm{OH}+\mathrm{OH} \rightarrow \mathrm{H}_{2} \mathrm{O}+\mathrm{O}$ & $9.50 \%$ \\
\hline $\mathrm{O}+\mathrm{OH} \rightarrow \mathrm{H}+\mathrm{O}_{2}$ & $9.24 \%$ \\
\hline $\mathrm{OH}+\mathrm{H}_{2} \mathrm{O}_{2} \rightarrow \mathrm{H}_{2} \mathrm{O}+\mathrm{HO}_{2}$ & $8.28 \%$ \\
\hline $\mathrm{OH}+\mathrm{HO}_{2} \rightarrow \mathrm{O}_{2}+\mathrm{H}_{2} \mathrm{O}$ & $4.17 \%$ \\
\hline Radial loss & $3.39 \%$ \\
\hline $\mathrm{e}+\mathrm{OH} \rightarrow \mathrm{O}+\mathrm{H}+\mathrm{e}$ & $2.57 \%$ \\
\hline $\mathrm{H}+\mathrm{OH}+\mathrm{H}_{2} \mathrm{O} \rightarrow \mathrm{H}_{2} \mathrm{O}+\mathrm{H}_{2} \mathrm{O}$ & $0.95 \%$ \\
\hline Others & $0.84 \%$ \\
\hline
\end{tabular}

According to the simulation results (table 5), the generation and loss of $\mathrm{H}_{2} \mathrm{O}_{2}$ is controlled mainly by heavy particle reactions, and in a first approximation the $\mathrm{H}_{2} \mathrm{O}_{2}$ density is determined by the balance between the three body association reaction with $\mathrm{OH}$ and the destruction of $\mathrm{H}_{2} \mathrm{O}_{2}$ induced by $\mathrm{OH}$. If the rest of processes are neglected, balance between the generation and loss due to these two reactions requires that $\mathrm{k}_{1} \mathrm{n}_{O H}^{2}=\mathrm{k}_{2} \mathrm{n}_{O H} \mathrm{n}_{H_{2} O_{2}}$, where $\mathrm{k}_{1}$ and $\mathrm{k}_{2}$ are the reaction rates of the two reactions (table 3). It then follows that the upper bound for the density ratio $\mathrm{n}_{\mathrm{H}_{2} \mathrm{O}_{2}} / \mathrm{n}_{\mathrm{OH}}=\mathrm{k}_{1} / \mathrm{k}_{2}$. At $350 \mathrm{~K}$, this ratio is 3.7 , larger than the 1.49 observed in simulations and experiments (table 4) indicating the importance of additional loss mechanisms. There seems to be a systematic overestimate of at least the $\mathrm{H}_{2} \mathrm{O}_{2}$ density, even in the fluid model. It should however be noted that the obtained $\mathrm{OH}$ densities compare very well with the experimental value $\left(310^{14} \mathrm{~cm}^{-3}\right)$ obtained in similar discharge with $2 \mathrm{~mm}$ gap at the same power density [36]. The following are the main factors believed to contribute to this discrepancy:

1. Regions of higher temperature than $348 \mathrm{~K}$. The density ratio decreases with increasing temperature and for example, if the temperature reached $450 \mathrm{~K}$, simulation results show that the density ratio would drop from 1.49 to 0.77 and the average $\mathrm{H}_{2} \mathrm{O}_{2}$ density from $3.2 \cdot 10^{14}$ to $1.7 \cdot 10^{14} \mathrm{~cm}^{-3}$. The temperature used in the simulations was measured in the electrode and somewhat higher temperatures should be expected in the gas phase.

2. The effective electron energy in the center of the discharge where the $\mathrm{H}_{2} \mathrm{O}_{2}$ concentration is maximum swings up to approximately $4 \mathrm{eV}$ (see figure 5) and hence it is possible that vibrational excitation of $\mathrm{H}_{2} \mathrm{O}_{2}$ would lead to enhanced destruction which is not included in the model, bringing the density ratio $\mathrm{n}_{\mathrm{H}_{2} \mathrm{O}_{2}} / \mathrm{n}_{\mathrm{OH}}$ closer to unity.

3. Despite our efforts in creating a comprehensive chemical model, it is possible that additional reactions need to be considered. 
4. The experimental accuracy of the measurement. The day-to-day reproducibility of the $\mathrm{H}_{2} \mathrm{O}_{2}$ production is within a factor 2 . The reproducibility of the $\mathrm{H}_{2} \mathrm{O}_{2}$ detection is much better and within $10 \%$. The accuracy of the power measurement is approximately $20 \%$. As the $\mathrm{H}_{2} \mathrm{O}_{2}$ density varies little with power (see figure 7), the power will not be a major source of error. In the far effluent, short lived species will have recombined and $\mathrm{O}_{3}$ is not abundantly produced in $\mathrm{He}-\mathrm{H}_{2} \mathrm{O}$ mixtures. The selectivity of the $\mathrm{H}_{2} \mathrm{O}_{2}$ detection is thus not an issue in the case of the presented experimental results.

5. The accuracy of the reaction rates. The key reaction of the production of $\mathrm{H}_{2} \mathrm{O}_{2}$ has a variation of a factor 2 at $350 \mathrm{~K}$ for the different sources as reported in [30]. This means that the ratio of the $\mathrm{OH}$ and $\mathrm{H}_{2} \mathrm{O}_{2}$ density is only accurate within a factor of 2 . Note that the experimental $\mathrm{OH}$ density is estimated from a balance equation. However, the calculated $\mathrm{OH}$ density corresponds within $30 \%$ with a direct measurement for the same discharge at the same power density but in a different reactor geometry.

\section{Conclusions}

The hydrogen peroxide production in a RF exited APGD operating with a $\mathrm{He}+\mathrm{H}_{2} \mathrm{O}$ has been investigated as a function of various plasma parameters. The maximum production efficiency reached in this work is $0.12 \mathrm{~g} / \mathrm{kWh}$. The gas temperature is measured to vary between 320 and $380 \mathrm{~K}$, being too low to cause important thermal dissociation of hydrogen peroxide. The $\mathrm{H}_{2} \mathrm{O}_{2}$ increases linearly with the $\mathrm{H}_{2} \mathrm{O}$ concentration up to $1 \%$ water, and increasing the power and flow rate increases the $\mathrm{H}_{2} \mathrm{O}_{2}$ density. Power modulation has little effect on the $\mathrm{H}_{2} \mathrm{O}_{2}$ production.

An estimate of species densities based on the balance of main production and destruction reactions are in line with literature reports that indicate that the main production process of $\mathrm{H}_{2} \mathrm{O}_{2}$ in an APGD is via the three body recombination of $\mathrm{OH}$. The main losses of $\mathrm{H}_{2} \mathrm{O}_{2}$ are due to losses to reactions with $\mathrm{OH}$ in the bulk, electron induced dissociation and surface losses in the reactor. These results are confirmed by a global model and a 1D fluid model. The agreement between model and experiment is very good and at a level corresponding to uncertainties in reaction rates and experimental accuracy. Validated and accuarte electron induced reaction rates for $\mathrm{H}_{2} \mathrm{O}_{2}$ are not reported in literature. However, time modulation of the RF power shows that electron induced losses of $\mathrm{H}_{2} \mathrm{O}_{2}$ are not dominant which is in agreement with the simulation results presented in this study.

\section{References}

1. P. Bruggeman, C. Leys, J Phys D: Appl Phys 42(5), 053001 (2009)

2. G. Goor, Catalytic Oxidations with Hydrogen Peroxide as Oxidant (Dordrecht, 1992)

3. R.A. Jones, W. Chan, M. Venugopalanlb, J Phys Chem 79(11), 89 (1969)

4. P. Anastas, N. Eghbali, Chem Soc Rev 39(1), 301 (2010). DOI 10.1039/B918763B

5. C.W. Jones, Application of Hydrogen Peroxide and Derivatives London (R Soc of Chem, London, 1990)

6. W. Eul, A. Moeller, N. Steiner, Hydrogen Peroxide (John Wiley \& Sons, LTD, 2000)

7. W. Hess, 4th ed., Kirk-Othmer Encyclopedia of Chemical Technology (Wiley, 1995)

8. R. Burlica, R. Grim, K.Y. Shih, D. Balkwill, B.R. Locke, Plasma Process Polym 7(8), 640 (2010)

9. B.R. Locke, K.Y. Shih, Plasma Sources Sci Technol 20(3), 034006 (2011)

10. D.X. Liu, P. Bruggeman, F. Iza, M.Z. Rong, M.G. Kong, Plasma Sources Sci Technol 19(2), 025018 (2010)

11. K. McKay, D.X. Liu, M.Z. Rong, F. Iza, M.G. Kong, J Phys D: Appl Phys 45(17) (2012)

12. B. Dodet, E. Odic, A. Goldman, M. Goldman, D. Renard, J Adv Oxid Technol 8(1), 91 (2005) 
13. M.J. Kirkpatrick, B. Dodet, E. Odic, International Journal of Plasma Environment Science and Technology 1, 96 (2007)

14. D. Porter, M.D. Poplin, F. Holzer, W.C. Finney, B.R. Locke, S. Member, A. Formation, IEEE Trans Ind Appl 45(2), 623 (2009)

15. A.F. Gutsol, V.K. Zhivotov, B.V. Potapkin, V.D. Rusanov, High Energ Chem 26(4), 228 (1992)

16. P. Bruggeman, F. Iza, D. Lauwers, Y.A. Gonzalvo, J Phys D: App Phys 43(1) (2010)

17. P. Bruggeman, F. Iza, P. Guns, D. Lauwers, M.G. Kong, Y.A. Gonzalvo, C. Leys, D.C. Schram, Plasmas Source Science and Technology 19(1) (2010)

18. N. Knake, S. Reuter, K. Niemi, V. Schulz-von der Gathen, J. Winter, J Phys D: Appl Phys 41(19), 194006 (2008)

19. F. Iza, J. Lee, M. Kong, Physl Rev Lett 99(7), 075004 (2007)

20. R.F.P. Nogueira, M.C. Oliveira, W.C. Paterlini, Talanta 66(1), 86 (2005)

21. M. Golkowski, C. Golkowski, J. Leszczynski, S.R. Plimpton, P. Maslowski, A. Foltynowicz, J. Ye, B. Mccollister, IEEE Trans Plasma Sci 40(8), 1984 (2012)

22. C.D. Wagner, R.H. Smith, E.D. Peters, Anal Chem 19(12), 976 (1947)

23. W.C. Schumb, C.N. Satterfield, R.L. Wentworth, Hydrogen Peroxide (Reinhold Publishing Corporation, New York, 1955)

24. P.J. Brandhuber, G. Korshin, Methods for the Detection of Residual Concentrations of Hydrogen Peroxide in Advanced Oxidation Processes (WateReuse Foundation, 2009)

25. R. Baldwin, D. Brattan, Chem Kinet 8(1), 110 (1966)

26. C.N. Satterfield, T.W. Stein, Ind Eng Chem 49, 1173 (1957)

27. S. Hofmann, A.F.H.V. Gessel, T. Verreycken, P. Bruggeman, Plasma Sources Sci Technol 20(6) (2011)

28. C. Laux, in Physico-Chemical Modeling of High Enthalpy and Plasma Flows, ed. by D. Fletcher, J.M. Charbonnier, G. Sarma, T. Magin (Karman Institute Lecture Series, Rhode-Saint-Genèse, Belgium, 2002), p. 2012

29. A. Yang, X. Wang, M. Rong, D. Liu, F. Iza, M.G. Kong, Physics of Plasmas 18(11) (2011)

30. NIST Chem Kinet Database. URL http://kinetics.nist.gov/kinetics/index.jsp

31. R. Forster, M. Frost, D. Fulle, H. Hamann, H. Hippler, A. Schlepegrell, J. Troe, J Chem Phys 103(8), 2949 (1995)

32. F. Tochikubo, S. Uchida, T. Watanabe, Jpn J Appl Phys, Part 1 43(1), 315 (2004)

33. D. Nandi, E. Krishnakumar, A. Rosa, W.F. Schmidt, E. Illenberger, Chem Phys Lett 373(5-6), 454 (2003)

34. G. Hagelaar, L. Pitchford, Plasma Sources Sci Technol 14(4), 722 (2005)

35. Y. Itikawa, N. Mason, J Phys Chem Ref Data 34(1), 1 (2005)

36. P.J. Bruggeman, G. Cunge, N. Sadeghi, Plasma Sources Sci Technol 21(3) (2012)

37. R. Atkinson, D.L. Baulch, R.A. Cox, J.N. Crowley, R.F. Hampson, R.G. Hynes, M.E. Jenkin, M.J. Rossi, Atmosp Chem Phys 4, 1461 (2004)

38. F.J. Gordillo-Vazquez, J Phys D: Appl Phys 41(23), 234016 (2008)

39. J. Waskoenig, K. Niemi, N. Knake, L.M. Graham, S. Reuter, V.S.v.D. Gathen, T. Gans, Plasma Sources Sci Technol 19(4), 045018 (2010)

40. I. Soloshenko, V. Tsiolko, V. Khomich, V. Bazhenov, a.V. Ryabtsev, a.I. Schedrin, I. Mikhno, IEEE Trans Plasma Sci 30(4), 1440 (2002)

41. IUPAC, IUPAC Subcommittee on Gas Kinetic Data Evaluation - Data Sheet PHOx2. Tech. rep., The IUPAC Subcommittee on GasKinetic Data Evaluation for Atmospheric Chemistry (2001) 


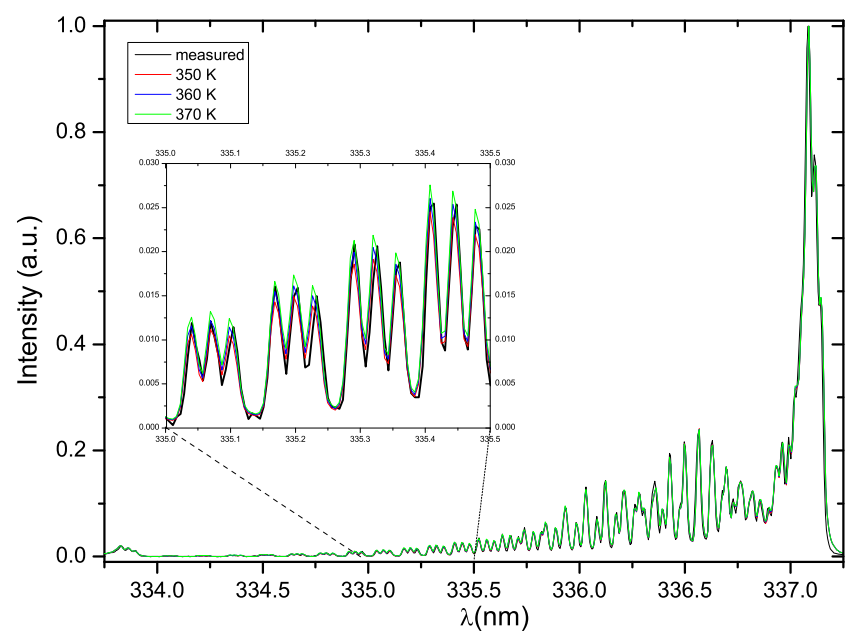

Fig. 4: Typical $\mathrm{N}_{2}(\mathrm{C}-\mathrm{B})(0-0)$ spectrum obtained with an addition of $0.1 \% \mathrm{~N}_{2}$ to the gas flow. The best fit leads to a rotational temperature of $360 \pm 25 \mathrm{~K}$ while the corresponding thermocouple measurement of the electrode yields $350 \pm 7 \mathrm{~K}$.

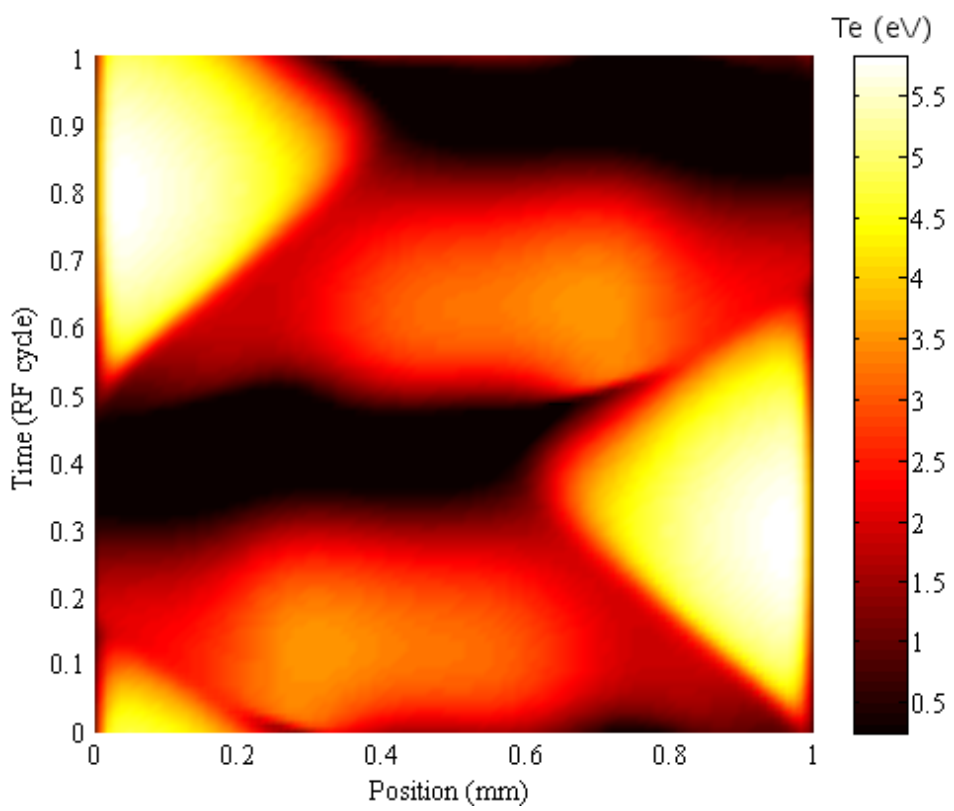

Fig. 5: Variation of the effective electron temperature (in units eV) as a function of position in the discharge gap and time during the RF cycle. Simulation results for $1 \mathrm{~mm}$ gap, 1.59 $\mathrm{W} / \mathrm{cm}^{2}$ at $13.5 \mathrm{MHz}, 2 \mathrm{slm}$ of $\mathrm{He}+0.47 \% \mathrm{H}_{2} \mathrm{O}$ at $T_{g}=348 \mathrm{~K}$. 


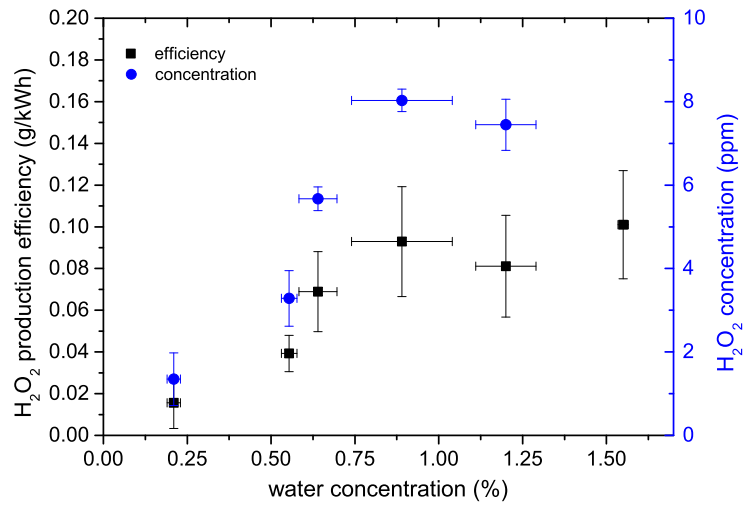

Fig. 6: The energy efficiency of the $\mathrm{H}_{2} \mathrm{O}_{2}$ production and the calculated corresponding gas phase densities as a function of varying water concentration at $1.8 \mathrm{~W} \pm 0.2 \mathrm{~W}$ and a flow rate of $2 \mathrm{slm}$.

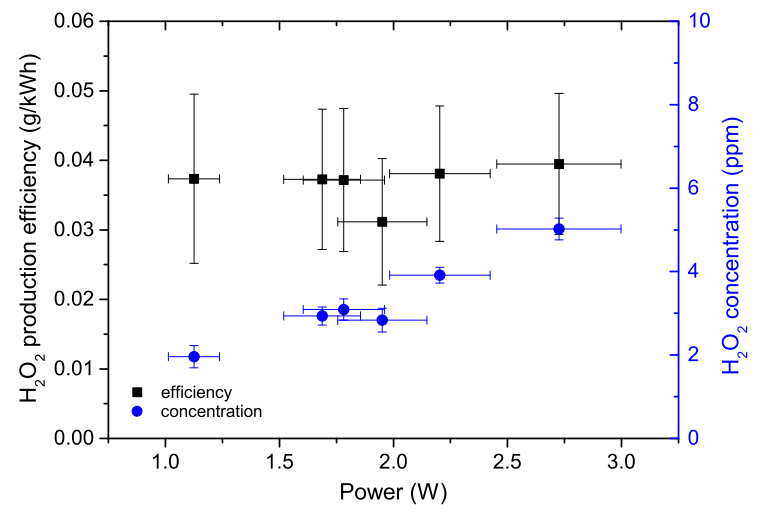

Fig. 7: The energy efficiency of the $\mathrm{H}_{2} \mathrm{O}_{2}$ production and the calculated corresponding gas phase densities as a function of varying the power at $0.6 \% \mathrm{H}_{2} \mathrm{O}$ and a flow rate of $2 \mathrm{slm}$. 


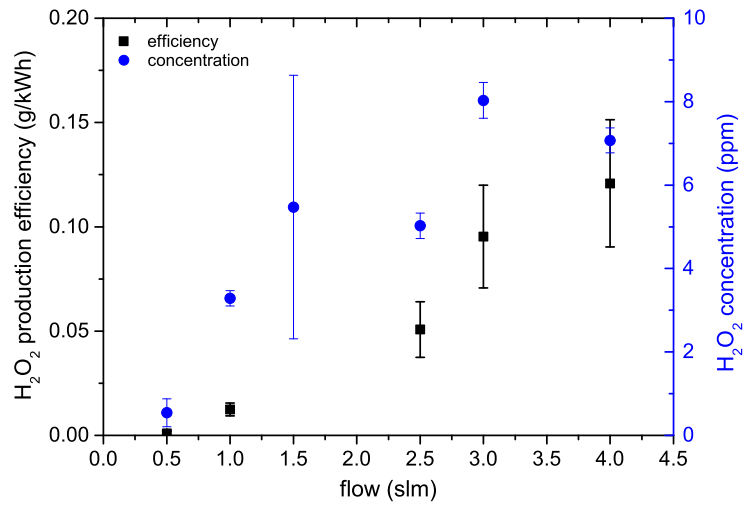

Fig. 8: The energy efficiency of the $\mathrm{H}_{2} \mathrm{O}_{2}$ production and the calculated corresponding gas phase densities as a function of varying gas flow at $0.47 \% \mathrm{H}_{2} \mathrm{O}$ and $2.7 \pm 0.2 \mathrm{~W}$ dissipated power.

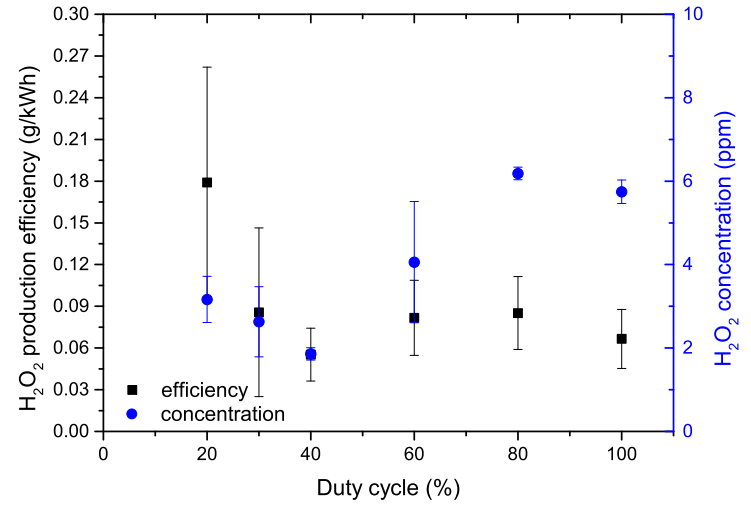

Fig. 9: The energy efficiency of the $\mathrm{H}_{2} \mathrm{O}_{2}$ production and the calculated corresponding gas phase densities as a function of varying duty cycle at $1.75 \pm 0.12 \mathrm{~W}$ constant instantaneous power and $0.6 \pm 0.1 \% \mathrm{H}_{2} \mathrm{O}$. 


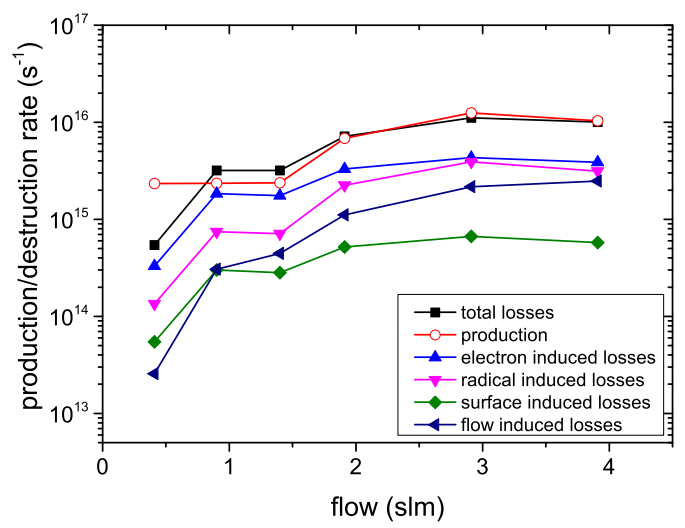

Fig. 10: Production and destruction rates of $\mathrm{H}_{2} \mathrm{O}_{2}$ as function of flow, at $2.7 \mathrm{~W}$ and $0.47 \%$ $\mathrm{H}_{2} \mathrm{O}$ based on the simple balance equation 1 .

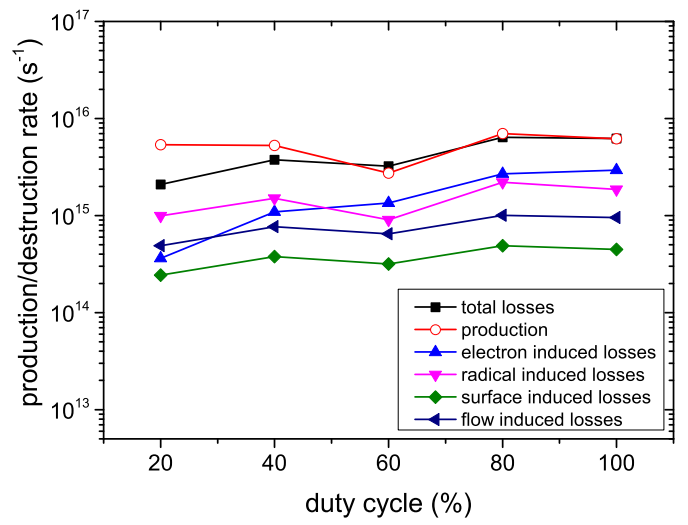

Fig. 11: Production and destruction rates of $\mathrm{H}_{2} \mathrm{O}_{2}$ as function of the duty cycle, at $1.75 \pm$ $0.12 \mathrm{~W}$ constant instantaneous power and $0.6 \pm 0.1 \% \mathrm{H}_{2} \mathrm{O}$ based on the simple balance equation 1 . 